\title{
COMPARATIVE STUDY BETWEEN SINGLE LAYER VERSUS DOUBLE LAYER ANASTOMOTIC TECHNIQUE FOR SMALL INTESTINAL ANASTOMOSIS IN ADULTS
}

By

\author{
Ahmed Abd El-Aal Sultan, Mohamed Kamal Soliman and Mohamed \\ Ibrahim El-Anany \\ Department of General Surgery, Faculty of Medicine, Al-Azhar University \\ Corresponding author: Ahmed Abd El-Aal Sultan \\ Phone: 01005056641, E-mail: dr.ahmedsultan@azhar.edu.eg \\ Orchid no: https://orcid.org/0000-0003-1097-2615
}

\begin{abstract}
Background: Anastomosis of gastrointestinal tract more commonly used in most of abdominal operations including esophagus, stomach, small intestine, large intestine, and biliary system. However single layer versus double layer anastomotic technique is still a matter of discussion as regard safety and efficacy.

Objective: To study efficacy and safety of single layer intestinal anastomosis against double layer anastomosis as regard leakage, cost effectiveness, and the time of the procedure.

Patients and methods: This prospective randomized study included 40 patients requiring small intestinal resection and anastomosis at Al- Hussein University Hospital and Damanhur Medical National Institute (AlBehira) during the period between May 2019 and October 2020. The cases of this study were subjected to full history taking, full clinical examination, along with routine laboratory and radiological investigations. The cases of this study were divided into two equal groups randomly; Group A was subjected to one-layer anastomosis, and group B underwent double layered anastomosis. All cases were subjected to the standard post-operative care. Oral intake and hospital stay were recorded. In addition, post-operative complications including leakage, ileus, and mortality were recorded.
\end{abstract}

Results: Mean time of operation in the single layer intestinal anastomosis was statistically significantly shorter as compared with double layered intestinal anastomosis $(28.29 \pm 8.15$ minutes and $35.19 \pm 9.96$ minutes) respectively. The early postoperative findings and late postoperative complications were comparable in both groups with no statistically significant difference.

Conclusion: Single layer intestinal anastomosis was less time consuming, less utilization of packing material, in addition to equal efficacy and safety as compared with double layer intestinal anastomosis.

Key words: Small bowel anastomosis, Single layer, Double layer, Intestinal leakage.

\section{INTRODUCTION}

The small intestine is a crucial component of the digestive system that allows for the breakdown and absorption of important nutrients. It is divided into the duodenum, jejunum, and ileum. Its wall consists of serosa, muscolaris, submucosa and, innermost mucosa (Campbell et al., 2019).

Small intestinal resection is a commonly performed procedure in both in elective and emergency surgeries. The 
length of the small bowel allows for simple resection without significant compromise to the gastrointestinal system function in most situations (Racz et al., 2012).

There are many reasons for performing a small bowel resection like malignancy, non-traumatic perforation, traumatic perforation and ischemic necrosis. Intestinal anastomosis is imperative for both practicing surgeons and residents to be familiar with and to master the art of safe bowel anastomosis. The technique of anastomosis depends upon the site of anastomosis, condition of the bowel and the underlying disease aetiology, and also the general condition of the patient (Goulder, 2012).

The process of intestinal anastomotic healing mimics that of wound healing elsewhere in the body in that it can be divided into an acute inflammatory (lag) phase, a proliferative phase, and finally, a remodeling a maturation phase (Rodrigues et al., 2019).

Many techniques have evolved but, the hand sewn suturing technique remains the mainstay for intestinal anastomosis because of availability and affordability of suture material and familiarity with the procedure (Luglio and Corcione, 2019).

Historically, double layer method has been method of choice however many reports have advocated the use of single layer anastomosis method for anastomosis because of lower rate of leak, time and cost effectiveness (Mohan et al., 2019).

Intestinal segments can be sewn together with various suture materials. The ideal suture material is one that causes minimal inflammation and tissue reaction, while providing maximum strength during the lag phase of wound healing. Double layered anastomosis typically consists of an inner layer of continuous or interrupted absorbable sutures and an outer layer of interrupted absorbable or nonabsorbable sutures. Single layered anastomosis consists of one layer of interrupted or continuous absorbable sutures (Khoorijestan et al., 2017).

Failure of an anastomosis with leakage of intestinal contents is one of the most significant surgical complications. Reported failure rates range from 1 to $24 \%$, depending on what type of anastomosis was performed and whether the operation was an elective or an emergency procedure. An anastomotic leak increases the morbidity and mortality associated with the operation; it can double the length of the hospital stay and increase the mortality by threefold ( $\mathrm{Sakr}$ et al., 2017).

The present work aimed to study the efficacy and safety of single layer intestinal anastomosis against double layer anastomosis in terms of anastomotic leakage, time taken for anastomosis and cost effectiveness.

\section{PATIENTS AND METHODS}

Our study was a prospective study to a total number of 40 patients whose age between 18 and 65 years requiring small intestinal resection and anastomosis (anastomosis between jejunum and jejunum, jejunum and ileum, and ileum and ileum anastomosis and stoma closure) at Al-Hussein University Hospital and Damanhur Medical National Institute (AlBehira) during the period between May 
2019 and October 2020. Both emergency and elective resections were included.

On the contrary, patients undergoing duodenal, colonic, or rectal anastomoses, hemodynamic instability, severe organ dysfunction, profuse intraoperative bleeding ( $>1$ liter), massive intestinal resection, immunocompromised cases, and post-operative ICU admission were excluded.

The cases of this study were subjected to full history taking, full clinical examination, along with routine laboratory and radiological investigations.

A written informed consent was taken from every patient before the surgical intervention. Besides, this study was approved by the local ethical committee of Al-Azhar University.

Patients were divided into two equal groups: Group A was subjected to single layered anastomosis, and group B was underwent double layered anastomosis.

All cases were performed under general anesthesia. After abdominal exploration, the diseased part of the small bowel was resected between two noncrushing clamps. This was done following ligation and division of the mesenteric blood supply of the resected part. The type of anastomoses was of end-to-end type in all cases.

The single layered anastomosis was done by continuous 3-0 polyglactin suture starting at the mesenteric border and was all-through of bowel wall including all layers. The double layered anastomosis was done by the following technique: continuous 3-0 polyglactin sutures for outer layer and continuous 3-0 polyglactin suture for the transmural inner layer. All the anastomoses were checked for their patency by milking the contents through the anastomosed parts. Then abdominal closure was done after inserting intraabdominal drains.

Following surgery, bowel rest, early immobilization, I.V fluids, and analgesia were ensured. Furthermore, abdominal examination was performed, and the appropriate laboratory or radiological investigations were ordered when required. Oral intake was started with sips of water after hearing intestinal sounds, and if the patient is clinically well.

Post-operative complications were documented including leakage, ileus, and in-hospital mortality. Clinical anastomotic failure was considered when there was leak of intestinal contents from the line of anastomosis between two hollow viscera [10]. Its diagnosis was mainly clinical as we depended on fever, tachycardia, abdominal distension, abdominal tenderness, rigidity, or appearance of intestinal secretions in the abdominal drain.

\section{Statistical analysis:}

Data were entered and analyzed using Microsoft Excel software. Data were then imported into Statistical Package for the Social Sciences (SPSS 22.0, IBM/SPSS Inc., Chicago, IL) software for analysis. Baseline characteristics of the study population were presented as frequencies and percentages (\%) or mean values and standard deviations (SD).

For comparison of data, Chi-Square test (or Fisher's exact test) was used to compare two independent groups of qualitative data. For quantitative data, independent-Samples t-test and Mann- 
Whitney U test were used to compare two groups of parametric and non-parametric quantitative data respectively. For all the included tests $\mathrm{P}$ values $<0.05$ are considered significant.

\section{RESULTS}

The mean age in group A (single layer) was $37.43 \pm 5.25$ years and in group B (double layer) was $39.65 \pm 6.09$ year. In group A (single layer), there were 14 (70\%) males and $6(30 \%)$ females. In group B (Double layer), there were 13 $(65 \%)$ males and $7(35 \%)$ females. There was no statistically significant difference regarding the age between the cases in the two study groups.
In group A, 17 cases were operated as emergency surgeries (85\%), while 3 cases were operated in elective situations $(15 \%)$. in group B 16 cases were operated as emergency surgeries (80\%), while 4 cases were operated in elective situations (\%20). In group $\mathrm{A}$, perforation due to trauma was diagnosed in 9 patients (45\%) while in group B seven cases (35\%) (Table1).

Table (1): Demographic data in the two studied groups

\begin{tabular}{|c|c|c|c|c|c|c|}
\hline \multirow{2}{*}{\multicolumn{2}{|c|}{ Parameters }} & \multirow{2}{*}{\multicolumn{2}{|c|}{$\begin{array}{c}\begin{array}{c}\text { Sigle layer } \\
\text { intestinal } \\
\text { anastomosis } \\
(\mathbf{N}=\mathbf{2 0})\end{array} \\
37.43 \pm 5.25\end{array}$}} & \multicolumn{2}{|c|}{$\begin{array}{l}\text { Double layer } \\
\text { intestinal } \\
\text { anastomosis } \\
(\mathrm{N}=20) \\
\end{array}$} & \multirow{2}{*}{$\begin{array}{c}\text { P value } \\
>0.05\end{array}$} \\
\hline & & & & & .09 & \\
\hline \multirow{2}{*}{ Sex } & Males & 14 & $70 \%$ & 13 & $65 \%$ & \multirow{2}{*}{$>0.05$} \\
\hline & Females & 6 & $30 \%$ & 7 & $35 \%$ & \\
\hline \multirow{2}{*}{$\begin{array}{c}\text { Type of } \\
\text { Operation }\end{array}$} & Emergency & 17 & $85 \%$ & 16 & $80 \%$ & \multirow{2}{*}{$>0.05$} \\
\hline & Elective & 3 & $15 \%$ & 4 & $20 \%$ & \\
\hline \multirow{5}{*}{ Diagnosis } & Trauma & 9 & $45 \%$ & 7 & $35 \%$ & \multirow{5}{*}{$>0.05$} \\
\hline & MVO & 3 & $15 \%$ & 4 & $20 \%$ & \\
\hline & Cancer & 1 & $5 \%$ & 1 & $5 \%$ & \\
\hline & $\begin{array}{c}\text { Srangulated } \\
\text { hernia }\end{array}$ & 4 & $20 \%$ & 4 & $20 \%$ & \\
\hline & $\begin{array}{c}\text { Closure of } \\
\text { stoma }\end{array}$ & 3 & $15 \%$ & 4 & $20 \%$ & \\
\hline
\end{tabular}

In both groups, anastomosis between ileum and ileum were performed in maximum number of patients, i.e. 19 $(47.5 \%)$ cases. In Group A, ileo-ileal anastomosis was done in $10(50 \%)$ cases. In Group B, ileo-ileal anastomosis was done in $9(45 \%)$ cases. The final number of (vicryl) packs needed in two-layered anastomosis was two, whereas in one- layer anastomosis needed just one pack of vicryl. Mean time consumed to fashion a single intestinal anastomosis was 28.29 \pm 8.15 minutes, while in double intestinal anastomosis was $35.19 \pm 9.96$ minutes with statistically significant difference between the both groups $(\mathrm{p}=0.001)$ (Table 2). 
Table (2): Operative data in the two studied groups

\begin{tabular}{|c|c|c|c|c|c|c|}
\hline \multicolumn{2}{|c|}{ 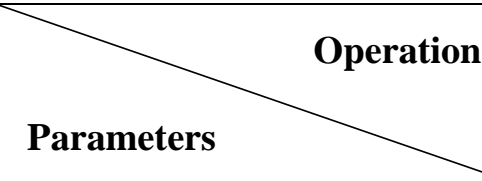 } & \multicolumn{2}{|c|}{$\begin{array}{l}\text { Single layered } \\
\text { intestinal } \\
\text { anastomosis } \\
(\mathrm{N}=\mathbf{2 0})\end{array}$} & \multicolumn{2}{|c|}{$\begin{array}{l}\text { Single layered } \\
\text { intestinal } \\
\text { anastomosis } \\
(\mathrm{N}=\mathbf{2 0})\end{array}$} & $P$ value \\
\hline \multirow{4}{*}{ Procedure } & Jejuno-jejunal & 3 & $15 \%$ & 5 & $25 \%$ & \multirow{4}{*}{$>0.05$} \\
\hline & Jejuno-ileal & 4 & $20 \%$ & 2 & $10 \%$ & \\
\hline & Ileo-ileal & 10 & $50 \%$ & 9 & $45 \%$ & \\
\hline & $\begin{array}{c}\text { Ileostomy } \\
\text { closure }\end{array}$ & 3 & $15 \%$ & 4 & $20 \%$ & \\
\hline \multicolumn{2}{|c|}{ Number of suture packs } & \multicolumn{2}{|c|}{1} & \multicolumn{2}{|c|}{2} & $>0.05$ \\
\hline \multicolumn{2}{|c|}{ Operative time (Min) } & \multicolumn{2}{|c|}{$28.29 \pm 8.15$} & \multicolumn{2}{|c|}{$35.19 \pm 9.96$} & 0.022 \\
\hline
\end{tabular}

The mean time of nasogastric tube in Group A was $1.91 \pm 0.75$ days and in Group B was $2.32 \pm 1.01$ days. There was no statistically significant difference between the return of bowel sounds between the both groups. In Group A, first intestinal sounds were after $2.42 \pm 1.11$ days, and start oral intake after $3.96 \pm$
0.66 days. In Group B, return of bowel sounds after $3.1 \pm 1.34$ days, and start oral intake after $4.08 \pm 0.79$ days. In our comparative study, the mean hospital stay duration in Group A was 5.90 \pm 1.43 days and in Group B it is $7.29 \pm 1.89$ days (Table 3).

Table (3): Early postoperative data in the two studied groups

\begin{tabular}{|c|c|c|c|}
\hline Operation & $\begin{array}{c}\text { Single layered } \\
\text { intestinal } \\
\text { anastomosis } \\
\text { Parameters }\end{array}$ & $\begin{array}{c}\text { Double layered } \\
\text { intestinal } \\
\text { anastomosis } \\
\text { (N=20) }\end{array}$ & P value \\
\hline $\begin{array}{c}\text { Duration of } \\
\text { nasogastric tube } \\
\text { (Days) }\end{array}$ & $1.91 \pm 0.75$ & $2.32 \pm 1.01$ & $>0.05$ \\
\hline $\begin{array}{c}\text { First intestinal } \\
\text { sounds } \\
\text { (Days) }\end{array}$ & $2.42 \pm 1.11$ & $3.1 \pm 1.34$ & $>0.05$ \\
\hline $\begin{array}{c}\text { Start of oral intake } \\
\text { (Days) }\end{array}$ & $3.96 \pm 0.66$ & $4.08 \pm 0.79$ & $>0.05$ \\
\hline Hospital stay (Days) & $5.90 \pm 1.43$ & $7.29 \pm 1.89$ & $>0.05$ \\
\hline
\end{tabular}

The total number of anastomotic leak was noted in $2(5 \%)$ patients. Anastomotic leak was observed in group A in one (5\%) patient, and occurred in group $\mathrm{B}$ in one
(5\%) patient. In Group A, three (15\%) cases had postoperative ileus, while in Group B there were 4 cases (\%20) (Table 4). 
Table (4): Postoperative complications in the two studied groups

\begin{tabular}{|c|c|c|c|c|c|}
\hline Operation & $\begin{array}{c}\text { Single layered } \\
\text { intestinal } \\
\text { anastomosis } \\
(\mathbf{N = 2 0})\end{array}$ & \multicolumn{2}{|c|}{$\begin{array}{c}\text { Double layered } \\
\text { intestinal } \\
\text { anastomosis } \\
(\mathbf{N = 2 0})\end{array}$} & P value \\
\hline Intestinal leakage & 1 & $5 \%$ & 1 & $5 \%$ & 1 \\
\hline Ileus & 3 & $15 \%$ & 4 & $20 \%$ & $>0.05$ \\
\hline
\end{tabular}

\section{DISCUSSION}

The goal of resection and anastomosis of the small intestine is to remove an irreversibly injured or abnormal segment of intestine and rejoin the open bowel ends in a manner that will optimize healing and restore luminal and mural integrity (Pathak et al., 2014).

This study assessed the efficacy and safety of single layered anastomosis in comparison with double layer anastomosis after intestinal resection (Slieker et al., 2013).

In the present study, anastomosis was done at different levels of small intestine. In group A (one layer), there were $70 \%$ males and $30 \%$ females. In group B (two layers), there were $65 \%$ males and $35 \%$ females. In group A, perforation due to trauma was diagnosed in maximum number of patients, i.e. $45 \%$, while in group B was $35 \%$. In both groups, anastomosis between ileum and ileum were performed in maximum number of patients, i.e. $47.5 \%$. The mean duration required to construct a single layer anastomosis was 28.29 minutes and 35.19 minutes for double layered anastomosis. Therefore, there was significant difference between time requirement for single and double anastomosis and less time duration required for single layer anastomosis.
Our result was consistent with the finding of Bhargava et al. (2016) and Kar et al. (2017).

Overall numbers of suture (vicryl) packs required in two-layered anastomosis were two, whereas in one-layer anastomosis only one pack of vicryl was needed.

Although different suture materials (silk) were used in other studies, they found that double layer anastomosis was costlier than its counterpart (Dandi et al., 2015 and Mohan et al., 2019).

In our comparative study, the mean hospital stay duration in single layer was 8.24 days and in double layer was 8.48 days. Kar et al. (2017) formed that 2 days more needed in double layer was noted, while Sai and Sugumar (2019) stated that the duration of stay is equal in each group.

The postoperative of intestinal sounds return was earlier in one-layer group in comparison to two layers group. There was no statistically significant difference between the return of bowel sounds between both groups. This was similar to Kar et al. (2017).

The number of anastomotic leak in our study was $5 \%$ in both operations. Kar et al. (2017) too observed no statistically significant difference in the rates of intestinal anastomosis between the both techniques. 
The point against double layer was that it ignores the basic principle to accurately opposing the clean-cut edges and large amount of ischemic tissue within the suture line which may increase the incidence of leak and excessive inversion which may lead to narrowing of lumen. However, single layer technique, employing extra mucosal sutures allowed for accurate opposition, incorporate the strongest layer (submucosa) of gut, causes minimal damage to submucosal vascular plexus and least disturbance to lumen (Mittal et al., 2015).

\section{CONCLUSION}

The time needed to perform a onelayered anastomosis of small intestine was significantly less in comparison to twolayered and less suture material. Also, there was no significant difference in anastomotic leak rate between two groups. Finally, one layer continuous technique was as safe as conventional two layers technique.

Conflict of Interest: Authors declare no conflicts of interest.

\section{REFERENCES}

\section{Bhargava GS, Singh $H$ and Singh}

J. (2016): Single or double layer intestinal anastomosis? International Surgery Journal, 3(4):2173-6.

2. Campbell, J., Berry, J. and Liang, Y. (2019): Anatomy and physiology of the small intestine. In: Yeo CJ (ed). Shackelford's Surgery of the Alimentary Tract. 8th ed. Philadelphia: Content Repository Only, pp. 817-841.
3. Dandi, P. P., Aaudichya, A. S., Juneja, I. A., Vaishanani, B. V. and Bhatt, J. G. (2015): A prospective comparative study of intestinal anastomosis, single layer extramucosal versus double layer. Int Res J Med Sci, 3(8): 2099-104.

4. Goulder F. (2012): Bowel anastomoses: the theory, the practice and the evidence base. World Journal of Gastrointestinal Surgery, 4(9):208-213.

5. Kar, S., Mohapatra, V., Singh, S., Rath, P. K. and Behera, T. R. (2017): Single layered versus double layered intestinal anastomosis: a randomized controlled trial. Journal of Clinical and Diagnostic Research: JCDR, 11(6): 153-154.

6. Khoorjestan, S. M., Rouhi, G. and Toolabi, K. (2017): An investigation of the effects of suture patterns on mechanical strength of intestinal anastomosis: an experimental study: Suture patterns and material for intestinal anastomosis. Biomedical Engineering/ Biomedizinische Technik, 62(4): 429-437.

7. Luglio, G. and Corcione, F. (2019): Stapled versus handsewn methods for ileocolic anastomoses. Techniques in coloproctology, 23(11):1093-1095.

8. Mittal, S., Singh, H., Singh, G., Munghate, A., Garg, A. and Yadav, M. (2015): A comparative 
study between single layer versus double layer closure in ileostomy reversal. Asian Journal of Medical Sciences, 6(2): 43-46.

9. Mohan, S., Agarwal, V. V. and Borgohain, D. (2019): a study of single layer v/s two-layer intestinal anastomosis. International Journal of Scientific Research, 8(11): 67-70.

10. Pathak, A., Rahaman, M. A. and Mishra, S. M. (2014): SingleLayer Versus Double Layer Intestinal Anastomosis of Small Bowel at Nepalgunj Teaching Hospital. Journal of Nepalgunj Medical College, 12(1): 35-38.

11. Racz J, Dubois L, Katchky A, and Wall W. (2012): Elective and emergency abdominal surgery in patients 90 years of age or older. Canadian Journal of Surgery, 55(5):322-328.

12. Rodrigues, M., Kosaric, N., Bonham, C. A. and Gurtner, G. C. (2019): Wound healing: a cellular perspective. Physiological Reviews, 99(1): 665-706.
13. Sai, K. L. and Sugumar, C. (2019): A comparative study of single layer extra mucosal versus conventional double layer anastomosis of intestines in elective and emergency laparotomy. International Surgery Journal, 7(1): 184-188.

14. Sakr, A., Emile, S. H., Abdallah, E., Thabet, W. and Khafagy, W. (2017): Predictive factors for small intestinal and colonic anastomotic leak: a multivariate analysis. Indian Journal of Surgery, 79(6): 555-562.

15.Slieker, J. C., Daams, F., Mulder, I. M., Jeekel, J. and Lange, J. F. (2013): Systematic review of the technique of colorectal anastomosis. JAMA surgery, 148(2): 190-201. 
در اسة مقارنة بين تقنية الطبقة المفردة و الطبقة المزدوجة لمفاغرة الأمعاء الدقيقة عند البالغين

أحمد عبد العال سلطان, محمد كمال سليمان, محمد إبراهيم العنانى الاعيل

قسم الجراحة العامة، كلية الطب، جامعة الأزهر

Phone: 01005056641, E-mail: dr.ahmedsultan@ azhar.edu.eg

Orchid no: https://orcid.org/0000-0003-1097-2615

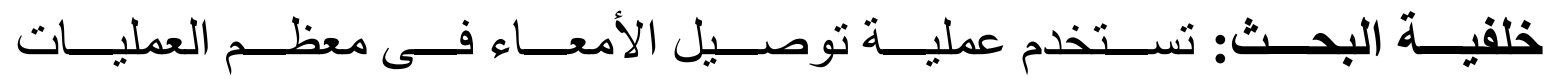

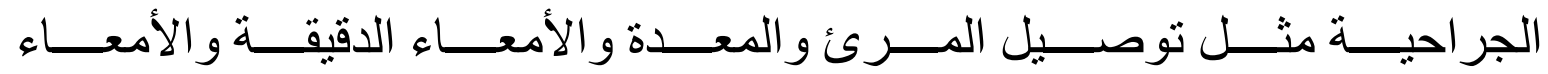

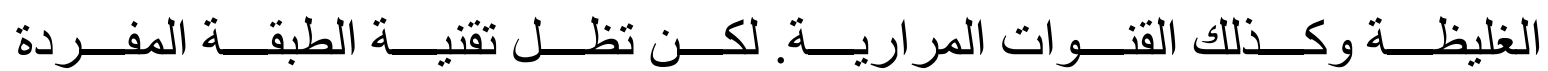
لتوصيل الأمعاء محل نقاش من ناحية الأمان و الكفاءة.

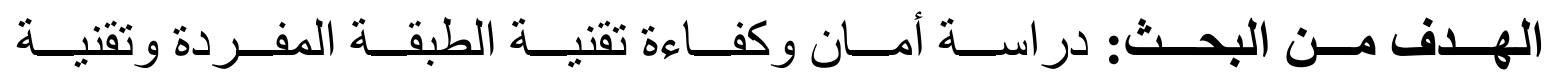
الطبقة المزدوجة من ناحية النسريب و التكلفة ووقت العملية.

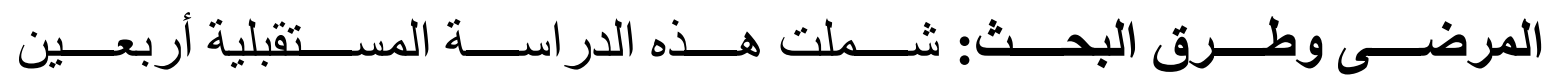

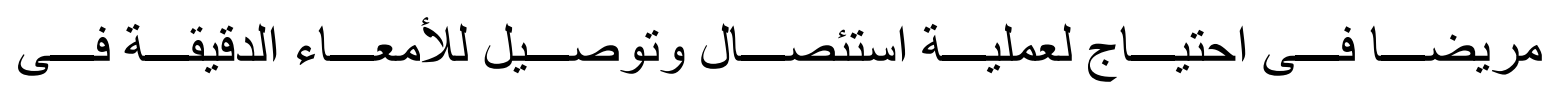

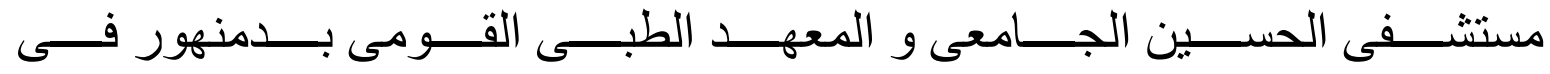

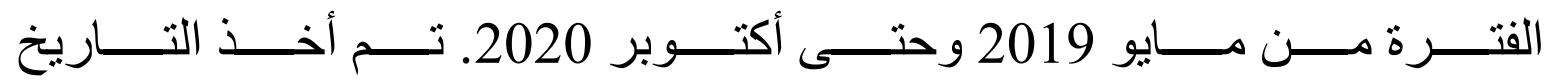

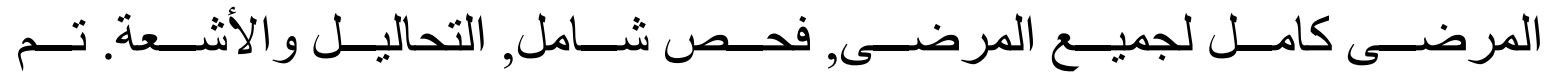

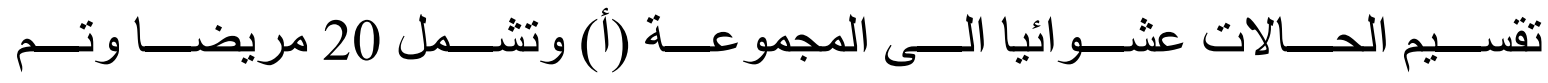

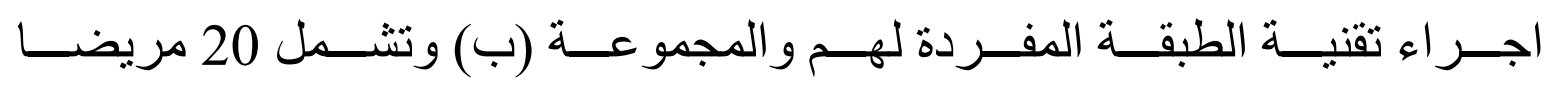

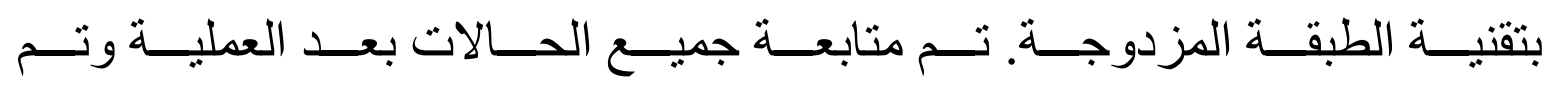

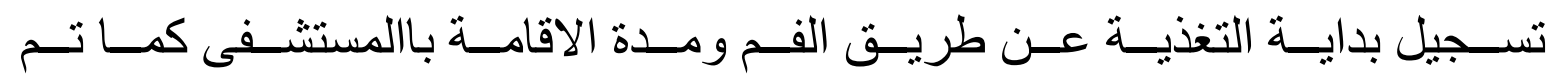




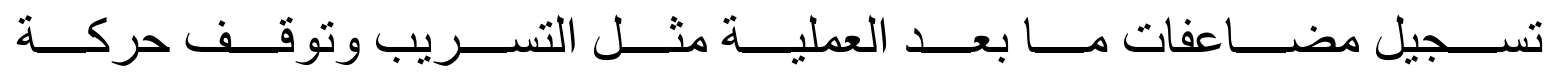
الامعاء.

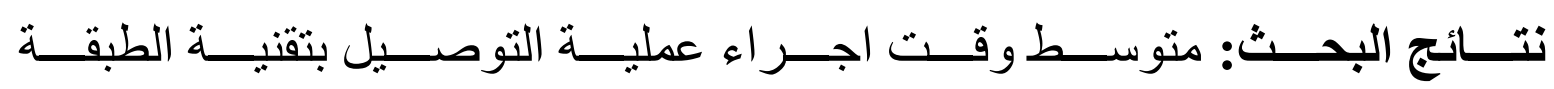

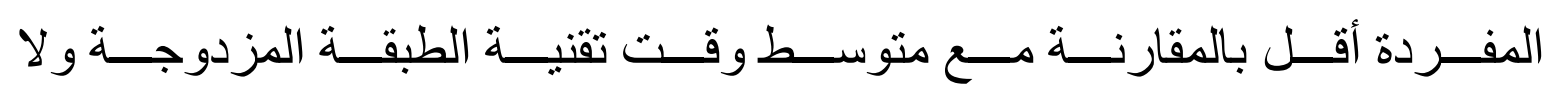
بوجد إختلاف بين مضاعفات ما بعد العملية بين الطربقتين.

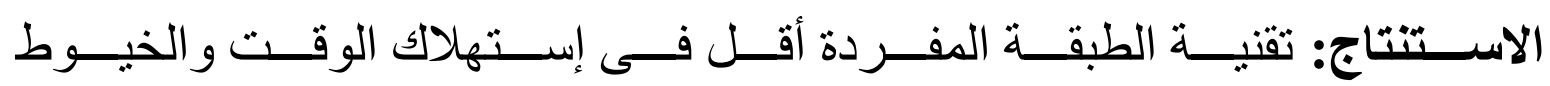
الجر احية ولها نفس الكفاءة بالنسبة لتقنية الطبقة المزدوجة.

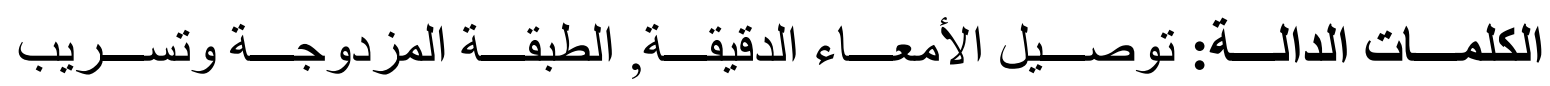
الأمعاء. 